\title{
Integration of Frequency Dependent Soil Electrical Properties in Grounding Electrode Circuit Model
}

\author{
Mehrdad Mokhtari, Zulkurnain Abdul-Malek, Chin Leong Wooi \\ Institute of High Voltage and High Current (IVAT), Faculty of Electrical Engineering, Universiti Teknologi Malaysia, \\ Johor, Malaysia
}

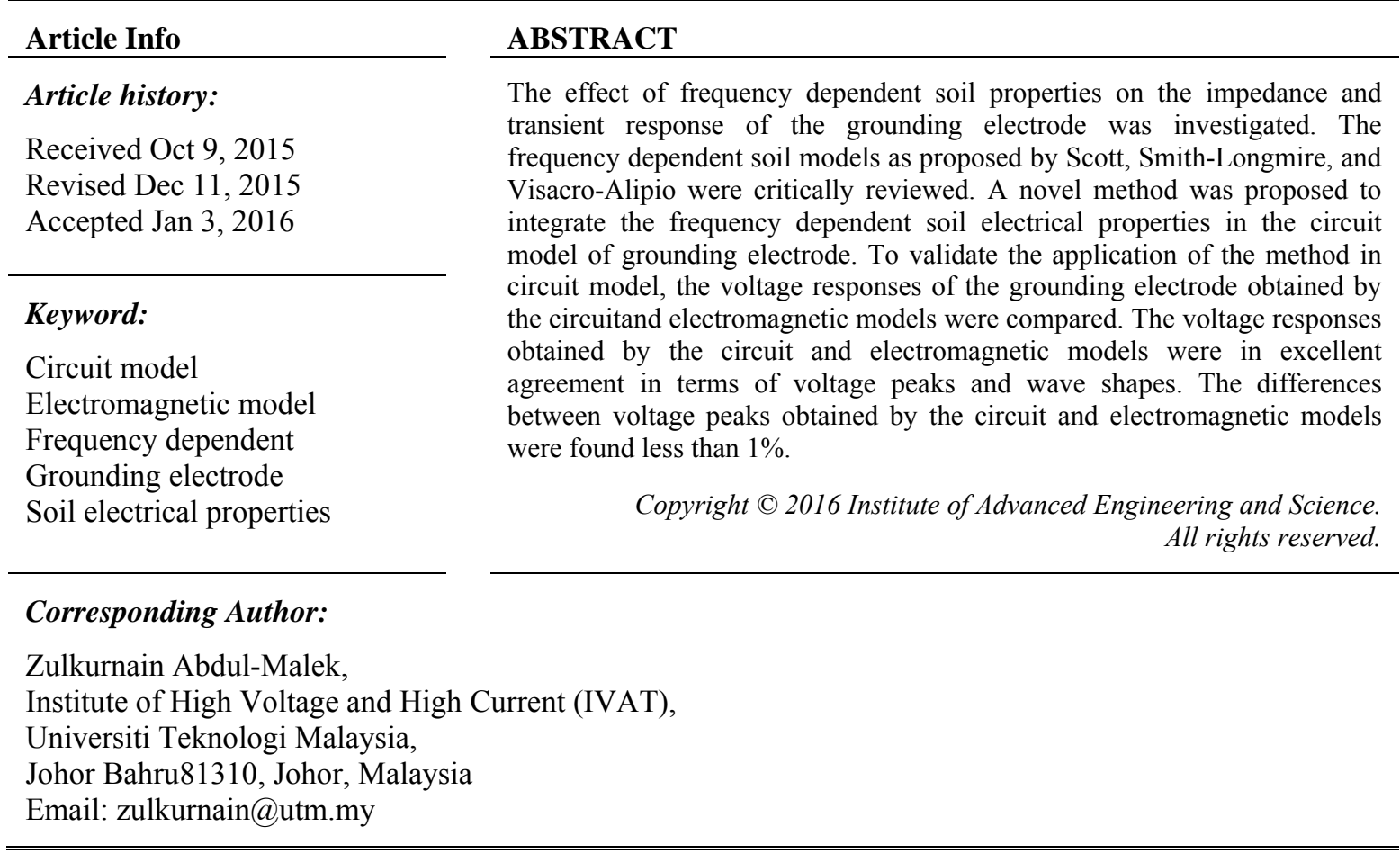

\section{INTRODUCTION}

Transient currents caused by faults and lightning strikes have significant effects on power system performance [1,2]. Thw high amplitude currents are dispersed into the earth through the grounding electrodes embedded inside the soil [3]. The performance of grounding electrodes is dependent on the soil electrical properties, electrode dimensions, and current parameters [4-7]. The soil conductivity and permittivity are influenced by several parameters such as soil compaction, temperature, moisture, and grain size [8]. In addition, they are also influenced by the frequency of the current. The higher the frequency, the lower the soil conductivity and permittivity $[9,10]$. As a result, the transient impedance of the electrode is also affected [11-14]. Despite all the above, the effect of frequency on soil electrical properties is usually disregarded in high frequency grounding system analyses. For instance, in CDEGS software (Current Distribution, Electromagnetic Fields, Grounding and Soil Structure Analysis program provided by the Safe Engineering Services and Technologies Ltd., Québec, Canada), the measured soil conductivity and soil permittivity are used in the computation, even though the conductivity and permittivity are usually measured by using either DC or low frequency sources. In addition, in circuit approach, the application of the frequency dependent soil properties in impulse condition is neglected. This is because applying each individual frequency of lightning current is difficult.

In this paper, the frequency dependent soil models as proposed by Scott [9], Smith-Longmire [15], and Visacro-Alipio [16] are critically reviewed. In addition, the simultaneous effect of frequency on both soil conductivity and permittivity, and hence on the grounding electrode impedance is discussed. A novel method is proposed to incorporate the frequency dependent soil electrical properties in circuit model of grounding electrode. The difference between the voltage responses obtained by the proposed method in the circuit 
model and obtained by the electromagnetic with the method of moment (EM-MoM) under first and subsequent return stroke currents was found less than $1 \%$.

The result shows that the influence of frequency on the grounding impedance and its transient performance must be taken into account when carrying out a grounding system transient analysis.

\section{FREQUENCY DEPENDENT SOIL MODELS}

Several models have been proposed to determine the soil electrical properties as a function of frequency $[9,15,16]$. In this section, the models proposed by Scott [9], Smith-Longmire [15], and VisacroAlipio [16] are described. In this study, the frequency dependent soil electrical parameters obtained by these models had been compared with the experimental values.

\subsection{Scott Model}

The frequency dependent conductivity, $\sigma(f)$, and frequency dependent relative permittivity, $\varepsilon(f)$, were determined using the formulas proposed by Scott [9] as

$$
\begin{aligned}
& \sigma(f)=0.028+1.098 \sigma_{0}-0.068 f+0.036 \sigma_{0}{ }^{2}-0.046 f \sigma_{0}+0.018 f^{2} \\
& \varepsilon_{r}(f)=5.491+0.946 \sigma_{0}-1.097 f+0.069 \sigma_{0}{ }^{2}-0.114 f \sigma_{0}+0.067 f^{2}
\end{aligned}
$$

where $\sigma_{0}$ is the nominal low frequency soil conductivity, and $f$ is the applied frequency in the range of $100 \mathrm{~Hz}$ to $1 \mathrm{MHz}$.

\subsection{Smith-Longmire Model}

The Smith and Longmire expressions were used to compute the soil relative permittivity and soil conductivity values. The frequency-dependent soil relative permittivity and conductivity are

$$
\begin{aligned}
& \varepsilon_{r}(f)=\varepsilon_{\infty}+\sum_{i=1}^{18} \frac{a_{i}}{1+\left(\frac{f}{F_{i}}\right)^{2}} \\
& \sigma(f)=\sigma_{D C}+2 \pi \varepsilon_{0} \sum_{i=1}^{18} a_{i} F_{i} \frac{\left(\frac{f}{F_{i}}\right)^{2}}{1+\left(\frac{f}{F_{i}}\right)^{2}}
\end{aligned}
$$

where $\sigma_{D C}$ is dc soil conductivity, $\varepsilon_{\infty}$ is high frequency limit of the dielectric constant, whichwas set to 5 . The value of coefficient $a_{i}$ was referred from Table 1 .

The parameters $F_{i}$ is obtained using

$$
F_{i}=F\left(\sigma_{D C}\right) \cdot 10^{i-1}
$$

Where

$$
F\left(\sigma_{D C}\right)=\left(125 \sigma_{D C}\right)^{0.8312}
$$

Table 1. Coefficient $a_{i}$

\begin{tabular}{cccc}
\hline$i$ & $a_{i}$ & $i$ & $a_{i}$ \\
\hline 1 & $3.40 \times 10^{6}$ & 8 & $1.25 \times 10^{1}$ \\
2 & $2.74 \times 10^{5}$ & 9 & $4.80 \times 10^{0}$ \\
3 & $2.58 \times 10^{4}$ & 10 & $2.17 \times 10^{0}$ \\
4 & $3.38 \times 10^{3}$ & 11 & $9.80 \times 10^{-1}$ \\
5 & $5.26 \times 10^{2}$ & 12 & $3.92 \times 10^{-1}$ \\
6 & $1.33 \times 10^{2}$ & 13 & $1.73 \times 10^{-1}$ \\
7 & $2.72 \times 10^{1}$ & & \\
\hline
\end{tabular}




\subsection{Visacro-Alipio Model}

The Visacro-Alipio expressions were obtained according to large number of field measurements. The frequency dependent relative permittivity and conductivity of soil were obtained using

$$
\begin{aligned}
& \varepsilon_{r}(f)=7.6 \times 10^{3} f^{-0.4}+1.3 \\
& \sigma(f)=\sigma_{0}\left[1+\left(1.2 \times 10^{-6}\left(\frac{1}{\sigma_{0}}\right)^{0.73}\right) \cdot(f-100)^{0.65}\right]
\end{aligned}
$$

where $\sigma_{0}$ is nominal low frequency soil conductivity, and $f$ is applied frequency in the range of $100 \mathrm{~Hz}$ to $4 \mathrm{MHz}$.

\subsection{Comparison of the Soil Models}

The frequency dependent soil properties obtained by Scott, Smith-Longmire, and Visacro-Alipio formulas were then compared with the experimental value to evaluate the accuracy of the soil models. Comparisons of the frequency dependent soil properties for low frequency soil resistivity values of $93.2 \Omega$.m, and $343 \Omega . \mathrm{m}$ are shown in Figures 1 and 2. As seen in both figures, all soil models were able to predict the frequency dependent soil resistivity values in different frequencies compared to the experimental values. However, in term of predicting the relative permittivity values, the Visacro-Alipio's soil model was found unable to properly predict the frequency dependent relative permittivity values.

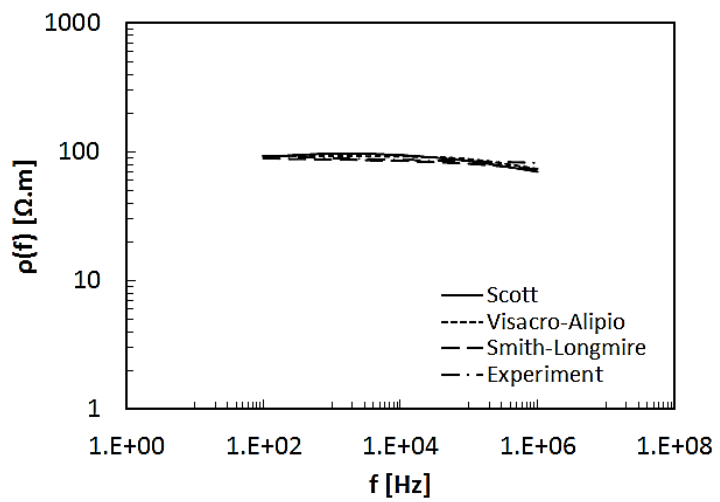

(a) $\rho(f)$

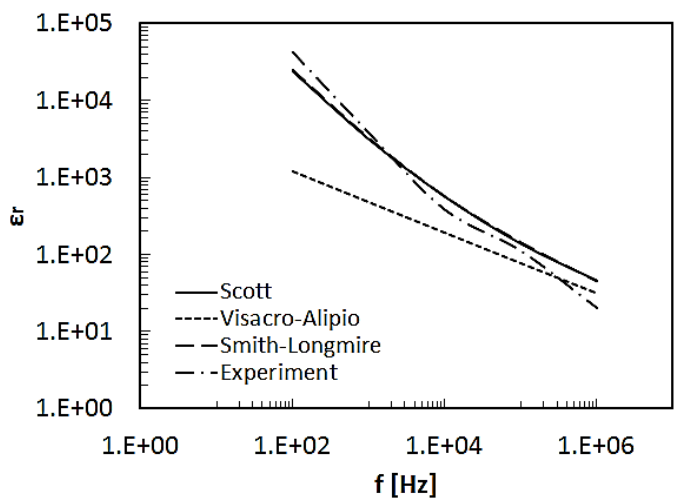

(b) $\varepsilon_{\mathrm{r}}(\mathrm{f})$

Figure 1. Frequency dependent soil electrical properties for $\rho_{0}=93.2 \Omega$.m obtained by different soil models

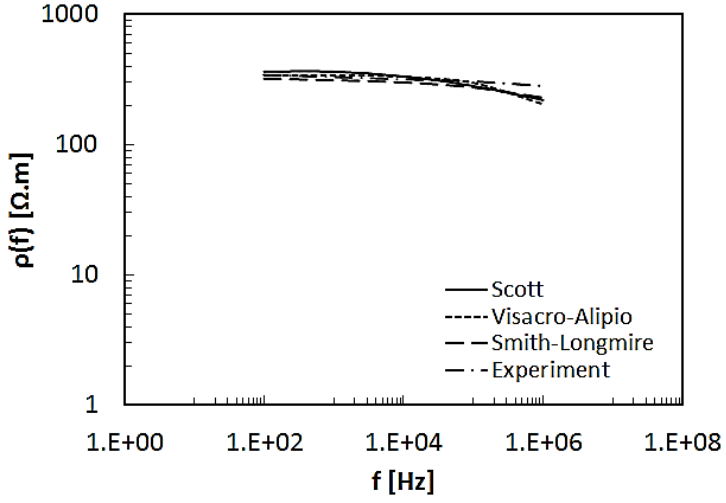

(a) $\rho(f)$

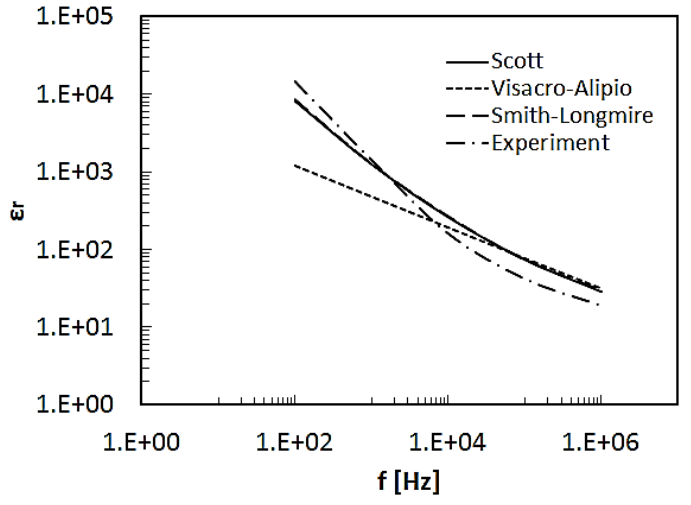

(b) $\varepsilon_{\mathrm{r}}(\mathrm{f})$

Figure 2. Frequency dependent soil electrical properties for $\rho_{0}=343 \Omega . \mathrm{m}$ obtained by different soil models 


\section{HARMONIC GROUNDING ELECTRODE IMPEDANCE CHARACTERISTIC}

This section discusses the effect of frequency on harmonic grounding electrode impedance under first and subsequent return stroke currents. A horizontal copper electrode with 10-m length and 5-mm radius was assumed located at 1-m depth in a uniform soil. Three different types of soil with low resistivity value ( $\rho=100 \Omega . \mathrm{m})$, and high resistivity value $(\rho=1000 \Omega . \mathrm{m})$ were considered.

The first return stroke current had a peak value of $30 \mathrm{kA}$, maximum steepness of $12 \mathrm{kA} / \mu \mathrm{s}$, and zero to peak time of $8 \mu \mathrm{s}$. The subsequent return stroke current had a peak value of $12 \mathrm{kA}$, a maximum steepness of $40 \mathrm{kA} / \mu \mathrm{s}$, and zero to peak time of $0.8 \mu \mathrm{s}$. The two waveforms were represented using Heidler's function [17], the parameters of which are given in [18].

The impedance characteristic of the electrodes according to the different soil models under first and subsequent return stroke currents are shown in Figures 3 and 4. The harmonic impedance was obtained as the ratio of grounding electrode voltage, and current as $Z(\omega)=V(\omega) / I(\omega)$. As seen in both figures, the harmonic impedance characteristics obtained by Scott and Smith-Longmire models were in accordance. The harmonic impedances obtained by Visacro-Alipio's model had large difference compared to the harmonic impedances obtained by Scott and Smith-Longmire models.

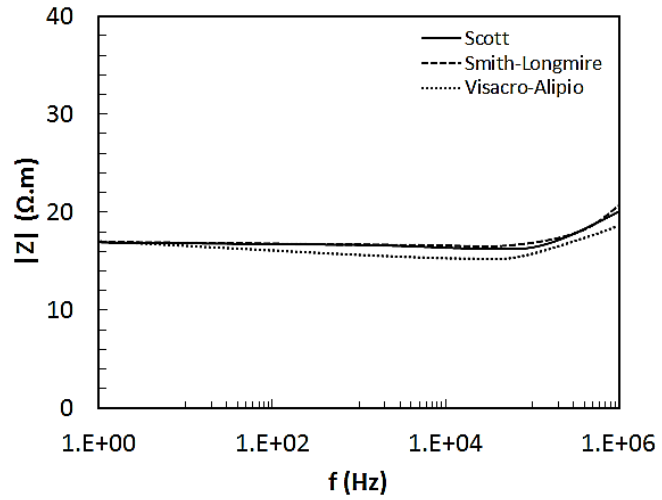

(a) Impedance

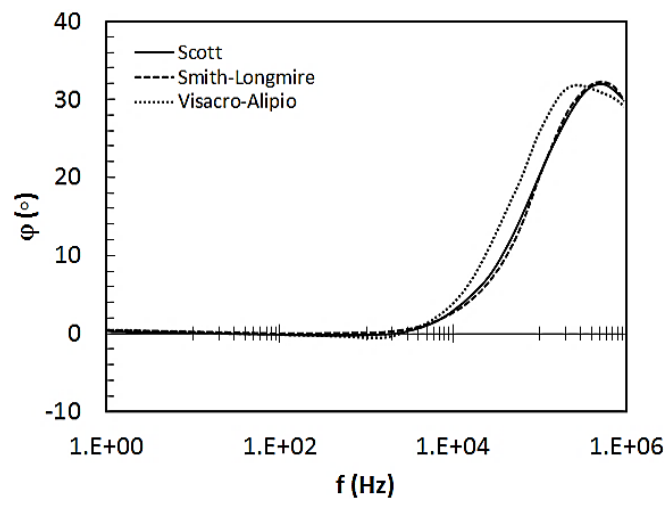

(b) Angle

Figure 3. Impedance characteristics of the grounding electrode $\rho_{0}=100 \Omega . \mathrm{m}$

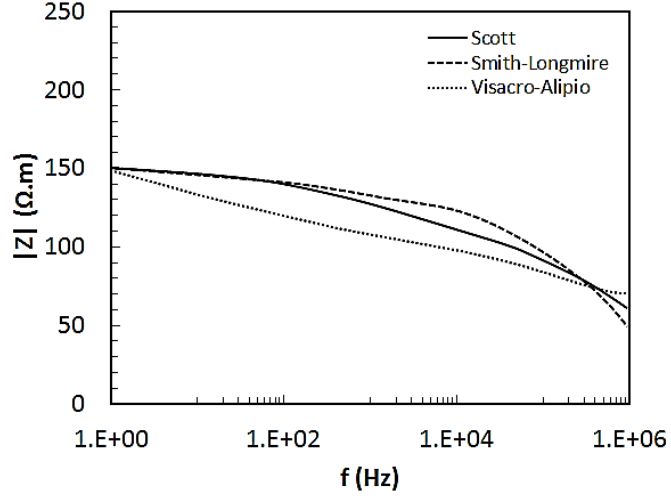

(a) Impedance

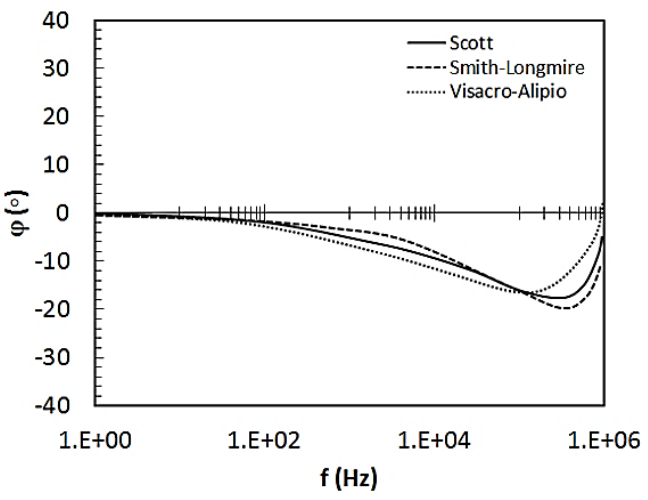

(b) Angle

Figure 4. Impedance characteristics of the grounding electrode $\rho_{0}=1000 \Omega . \mathrm{m}$

\section{TIME DOMAIN VOLTAGE RESPONSE OF THE ELECTRODE}

This section discusses the determination of the voltage response of the electrode with respect to the frequency dependent soil properties through computation. A novel method was applied to integrate the frequency dependent soil properties in circuit approach. This method improved the voltage response of the electrode with respect to the frequency dependent soil properties. 


\subsection{Electromagnetic Model with the Method of Moment}

The electromagnetic model with the method of moment is known as the most accurate model to analyze the grounding electrode. The methodology used in the electromagnetic model in disscussed. However, more details can be found in [19]. In electromagnetic approach with the method of moment (EMMoM), the injected current is specified as an impulse signal. Fast Fourier transform (FFT) was used to decompose the time domain current $i(t)$ into its corresponding frequency spectrum $i(\omega)$. The discrete frequency spectrum of the input current was in a range from the lowest frequency to the highest frequency (Nyquist frequency). First, the electrode was discretized into $N$ equal conductor segments. The current in each segment was then determined by applying MoM to enforce the continuity of the tangential component of the electric field along the segments. Once the current in each conductorsegment was known, the electric field $(E)$ caused by the currents at all computation points in the soil could be obtained. Consequently, other electromagnetic field values and derived quantities, such as electrode voltage, could also be obtained. To obtain the voltage in time domain, fast inverse Fourier transform (IFFT) was applied.

\subsection{Circuit Model}

A grounding electrode can be presented as an equivalent lumped circuit model [20, 21]. The model contains $R, L$, and $C$ elements. Since the soil ionization factor was not taken into account in this study due to the application of low amplitude current, Rudenberg circuit model, as illustrated in Figure 5 [20], was used to model the grounding electrode. The $R-L-C$ elements were set as the grounding resistance $R$ in $\Omega$ (or alternatively, the conductance $G$ in S), the electrode inductance $L$ in $\mu \mathrm{H}$, and the soil capacitance $C$ in F. Note that under fast-fronted currents, the proposed method in [21] was taken into account to determine the electrode inductance. For a horizontal grounding electrode in a uniform soil, the circuit elements could be obtained using the formulas initially proposed by Sunde [22]:

$$
\begin{aligned}
& R=\frac{1}{G}=\frac{\rho}{\pi l}\left[\ln \left(\frac{2 l}{\sqrt{2 a d}}\right)-1\right] \\
& L=\frac{\mu l}{2 \pi}\left[\ln \left(\frac{2 l}{a}\right)-1\right] \\
& C=\frac{\rho \varepsilon}{R}
\end{aligned}
$$

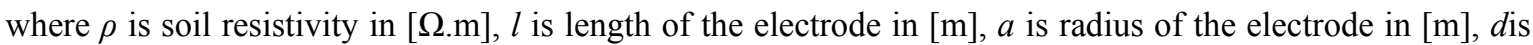
burial depth in [m], $\mu$ is soil permeability $(4 \pi \times 10-7 \mathrm{H} / \mathrm{m})$, and $\varepsilon$ is permittivity of soil in [F/m]. Obviously, the important material properties seen in (9) to (11) are $\rho, \mu$, and $\varepsilon$ for the resistance, inductance, and capacitance, respectively. However, only the resistivity and permittivity are frequency dependent, and hence only these two parameters were considered in this work.

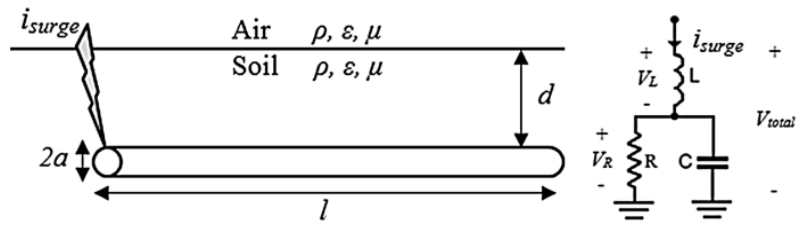

Figure 5. Representation of a typical grounding electrode by an equivalent lumped circuit model

It is known that the circuit approach is a simple approach compared to the electromagnetic approach to analyze the transient behavior of the grounding electrode. However, the difficulty of incorporating the frequency dependent soil properties limits the application of the approach in transient analysis, since the lightning current has frequency components. To investigate the effect of lightning current's front time, $T_{f}$, on the resistivity and permittivity, the equivalent frequency, $f_{e q}$, of the lightning current [23, 24]was determined using

$$
f_{e q}=\frac{1}{4 T_{f}}
$$


$f_{e q}$ was then used in frequency dependent soil properties soil models. Finally, the circuit element values of the electrode model as shown in Figure 5 with the frequency dependent soil properties were obtained.

\section{VALIDATION OF THE METHOD}

For validation, the voltage responses obtained by the circuit model and EM-MoMwere compared. In this comparison, the typical electrode and lightning currents defined in Section 2 were taken into account. The equivalent frequencies for the first and subsequent return stroke currents were $f_{e q}=31.25 \mathrm{kHz}$ and $f_{e q}=312.5 \mathrm{kHz}$, respectively. Scott soil model was taken into account to determine the frequency dependent soil properties. The voltage responses obtained by the circuit and EM-MoMwere in excellent agreement in terms of both peak values and waveforms as shown in Figures 6 and 7. The differences between voltage peaks obtained by the circuit model and EM-MoM for the first and subsequent return stroke currents when $\rho_{0}=100 \Omega$.m were $0.5 \%$ and $0.5 \%$, respectively. In addition, the differences between voltage peaks obtained by the circuit model and EM-MoM for the first and subsequent return stroke currents when $\rho_{0}=1000 \Omega$.m were $0.9 \%$ and $1 \%$, respectively. These differences prove that integrating the frequency dependent soil properties in the application of equivalent frequency in circuit model is an appropriate method in circuit approach.

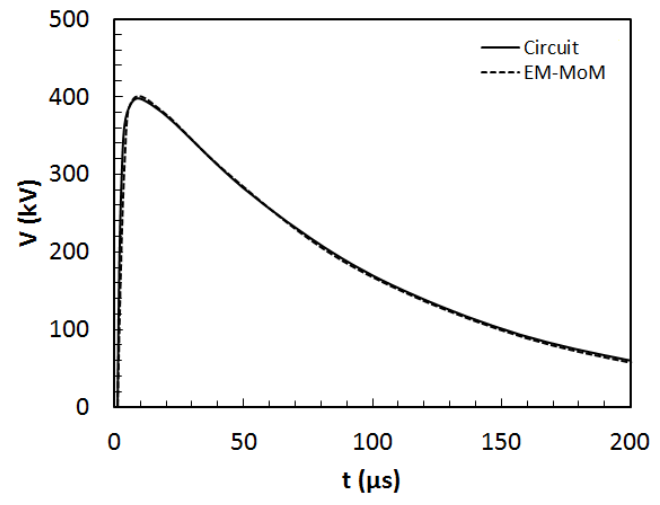

(a) Response to first return stroke

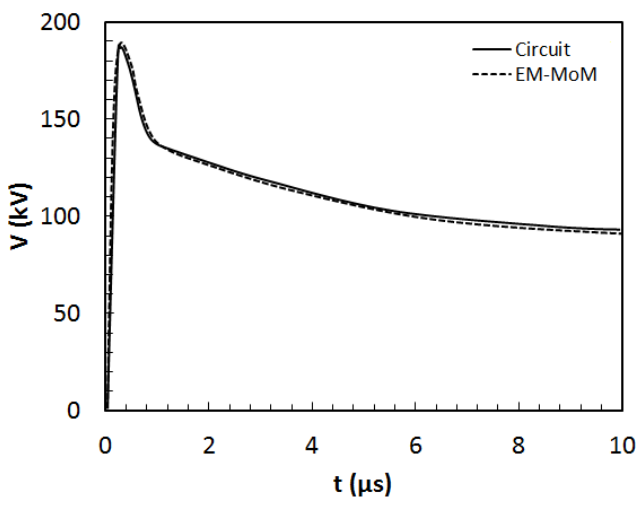

(b) Response to subsequent return stroke

Figure 6. Voltage responses obtained by the circuit and EM-MoM for $\rho_{0}=100 \Omega . \mathrm{m}$

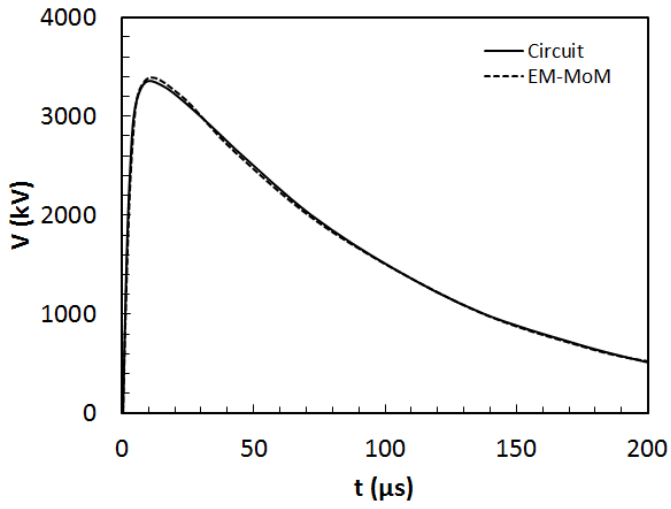

(a) Response to first return stroke

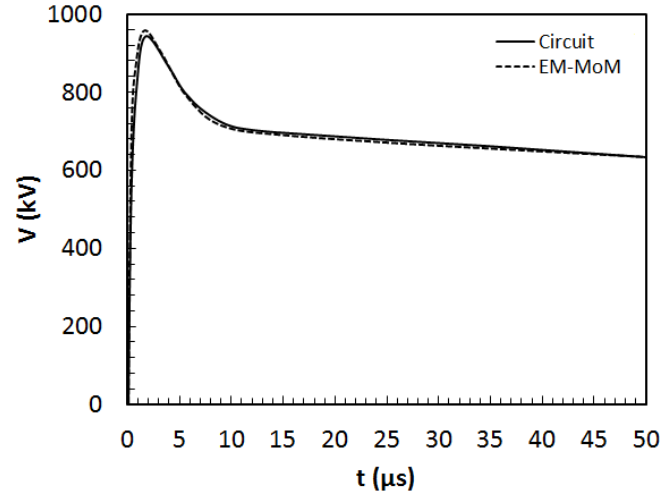

(b) Response to subsequent return stroke

Figure 7. Voltage responses obtained by the circuit and EM-MoM for $\rho_{0}=1000 \Omega . \mathrm{m}$

\section{CONCLUSION}

The frequency dependent soil models have been reviewed. The accuracy of the models has been investigated by comparing the results obtained by the models and experimental values. The comparison among the models and experimental values show that Scott and Smith-Longmire models are more accurate 
compared to the Visacro-Alipio's model. The effect of the frequency dependent soil electrical properties on grounding electrode impedance has been investigated by using the frequency dependent soil models. It is found that the impedance of the typical grounding electrode buried in soil changes as a function of frequency. The characteristic of the grounding electrode is found dependent on the soil resistivity. The characteristics of the grounding electrode in low resistivity and high resistivity soils are dominantly capacitive and inductive, respectively. In addition, a novel method is proposed to improve the voltage response of the electrode obtained by the circuit model of the grounding electrode. The application of the method in circuit model shows that the voltage responses obtained by the proposed method and electromagnetic model are in excellent agreement in terms of peak value and wave shape. The differences between the voltage peaks obtained by the proposed method and electromagnetic model are found less than $1 \%$. This finding shows that an overall improvement of grounding electrode performance can be achieved by applying the proposed method into the circuit models of the grounding electrodes when carrying out transient grounding analyses.

\section{ACKNOWLEDGEMENTS}

This work was supported in part by the Malaysian Ministry of Higher Education and Universiti Teknologi Malaysia, Grant Numbers 4F291and 10H61.

\section{REFERENCES}

[1] Zahri M, Menchafou Y, El Markhi H, Habibi M. Simplified method for single line to ground-fault location in electrical power distribution systems. International Journal of Electrical and Computer Engineering. 2015; 5(2): 221-30.

[2] Chunhua L, Weiran W, Jie S, Tao L. Lightning Performance and its Prevention for Quadruple-circuit Transmission Line with $220 \mathrm{kV} / 110 \mathrm{kV}$ Voltage in a Tower. TELKOMNIKA. 2013; 11(10): 5833-41.

[3] Zhu X, Zhang J, Ping Z, Liu J. Grounding Resistance Measurement of Transmission Towers in Mountainous Area. TELKOMNIKA. 2013; 11(8): 4439-46.

[4] Mokhtari M, Abdul-Malek Z, Salam Z. The effect of soil ionization on transient grounding electrode resistance in non-homogeneous soil conditions. International Transactions on Electrical Energy Systems. Published online in Wiley Online Library (wileyonlinelibrary.com). DOI: 10.1002/etep.2157, 2015.

[5] Mokhtari M, Abdul-Malek Z. The Effect of Grounding Electrode Parameters on Soil Ionization and Transient Grounding Resistance using Electromagnetic Field Approach. Applied Mechanics and Materials. 2014; 554: 628-32.

[6] Mokhtari M, Abdul-Malek Z. Influence of Soil Ionization on Earthing System Performance In: Z. Abdul Malek, editor. Progress Earthing Studies for Modern Life Style. $1^{\text {st }}$ ed. Johor Bahru, Malaysia: Universiti Teknologi Malaysia; 2015.

[7] Mokhtari M, Abdul-Malek Z. A Critical Review on Soil Ionisation Modelling for Grounding Electrodes. Archives of Electrical Engineering. forthcoming, 2016; 65(257): 1-11.

[8] He J, Zeng R, Zhang B. Methodology and Technology for Power System Grounding $1^{\text {st }}$ ed. Singapore: John Wiley \& Sons; 2013.

[9] Electrical and Magnetic Properties of Rock and Soil. Theoretical Notes, Note 18, U.S. Geological Survey; 1986 [cited 30 November 2015]. Available from: https://www.ece.unm.edu/summa/notes/Theoretical.html1983.

[10] Bigelowand RC, Eberle WR. Empirical predictive curves for resistivity and dielectric constant of earth materials: $100 \mathrm{~Hz}$ to $100 \mathrm{MHz}$. Open-File Report 83-911, US Geological Survey, 1972.

[11] Cavka D, Mora N, Rachidi F. A Comparison of Frequency-Dependent Soil Models: Application to the Analysis of Grounding Systems. IEEE Transactions on Electromagnetic Compatibility. 2014; 56(1): 177-87.

[12] Alipio R, Visacro S. Frequency Dependence of Soil Parameters: Effect on the Lightning Response of Grounding Electrodes. IEEE Transactions on Electromagnetic Compatibility. 2013; 55(1): 132-9.

[13] Alipio R, Visacro S. Impulse Efficiency of Grounding Electrodes: Effect of Frequency-Dependent Soil Parameters. IEEE Transactions onPower Delivery. 2014; 29(2): 716-23.

[14] Akbari M, Sheshyekani K, Alemi MR. The Effect of Frequency Dependence of Soil Electrical Parameters on the Lightning Performance of Grounding Systems. IEEE Transactions on Electromagnetic Compatibility. 2013; 55(4): 739-46.

[15] Smith KS, Longmire CL. A universal impedance for soils. Defense Nuclear Agency, Alexandria,VA, USA, Topical Report, 1975.

[16] Visacro S, Alipio R. Frequency Dependence of Soil Parameters: Experimental Results, Predicting Formula and Influence on the Lightning Response of Grounding Electrodes. IEEE Transactions on Power Delivery. 2012; 27(2): 927-35.

[17] Heidler F. Analytische Blitzstromfunktion zur LEMP-Berechnung. $18^{\text {th }}$ International Conference on Lightning Protection. Munich. 1985; 1: 16-20.

[18] Rachidi F, Janischewskyj W, Hussein AM, Nucci CA, Guerrieri S, Kordi B, et al. Current and electromagnetic field associated with lightning-return strokes to tall towers. IEEE Transactions on Electromagnetic Compatibility. 2001; 43(3): 356-67.

[19] Grcev L, Dawalibi F. An electromagnetic model for transients in grounding systems. IEEE Transactions on Power Delivery. 1990; 5(4): 1773-81.

Integration of Frequency Dependent Soil Electrical Properties in Grounding Electrode ... (Zulkurnain A.M.) 
[20] Rudenberg R. Electrical Shock Waves in Power Systems. Cambridge, MA:Harvard University Press, 1986.

[21] Mokhtari M, Abdul-Malek Z, Salam Z. An Improved Circuit-Based Model of a Grounding Electrode by Considering the Current Rate of Rise and Soil Ionization Factors. IEEE Transactions on Power Delivery. 2015; 30(1): 211-9.

[22] Sunde ED. Earth Conduction Effects in Transmission Systems. 2nd ed. New York: Dover; 1968.

[23] Stoll RL, Chen G, Pilling N. Comparison of two simple high-frequency earthing electrodes. IEEProceedings on Generation, Transmission and Distribution. 2004; 151(2): 219-24.

[24] Bellaschi PL, Armington RE, Snowden AE. Impulse and 60-Cycle Characteristics of Driven Grounds - II. Transactions of the American Institute of Electrical Engineers. 1942; 61(6): 349-63.

\section{BIOGRAPHIES OF AUTHORS}

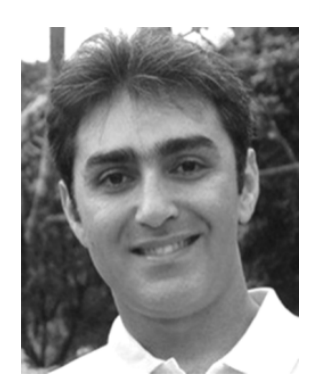

M. Mokhtari received the B.Sc. degree inelectrical engineering from the University of Applied Science and Technology, Tehran, Iran, in 2003, the M.E. degree in electrical engineering from the Universiti Teknologi Malaysia, Johor, Malaysia, in 2013, and is currently pursuing the Ph.D. degree in electrical engineering at the Institute of High Voltage and High Current (IVAT), Universiti Teknologi Malaysia. His research interest includes the high voltage engineering, the power system transient simulation, software development forhigh-frequency grounding systems, and insulation coordination.

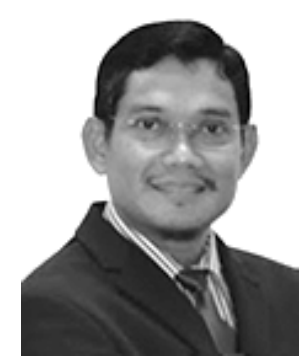

Z. Abdul-Malek received the B.E. degree in electrical and computer systems from Monash University, Melbourne, Australia, in 1989, the M.Sc. degree in electrical and electromagnetic engineering with industrial applications from the University of Wales Cardiff, Cardiff, U.K., in 1995 and the Ph.D. degree in high voltage engineering from Cardiff University, Cardiff, U.K., in 1999.He was a Lecturer with Universiti Teknologi Malaysia (UTM) for 26 years, where he is currently a Professor of High Voltage Engineeringwith the Faculty of Electrical Engineering. He is currently the Director of the Institute of High Voltage and High Current (IVAT), UTM. He has published two books, and has authored and co-authored more than 100 papers in varioust echnical journals and conference proceedings. His research interests includehigh-voltage instrumentation, lightning protection, detection and warning systems, partial discharges, nanodielectrics, and condition monitoring of power equipments.

Professor Abdul-Malek is actively involved in many national committees. He is the Chairman, Working Group on High-Voltage and High-Current Test Techniques. He is also a member of IEC Certification Body Management Committee, Technical Committee on High Voltage Power Transmission, Working Group on High Voltage Switchgear and Controlgears, Technical Working Group for ElectricalTesting, and Department of Standards IEC 17025 Technical Assessors. He is amember of the Power and Energy Society, Dielectrics and Electrical Insulation Society, and CIGRE.

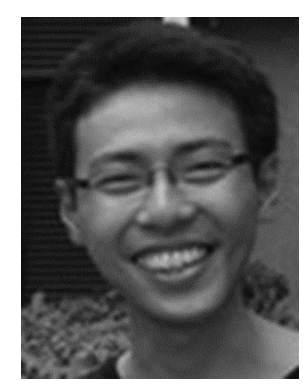

C. L. Wooi received the B.Sc. degree in electrical and electronic engineering from the Universiti Malaysia Sabah, Malaysia, in 2011, the M.E. degree in electrical engineering from the Universiti Teknologi Malaysia, Johor, Malaysia, in 2013, and is currently pursuing the Ph.D. degree in electrical engineering at the Institute of High Voltage and High Current (IVAT), Universiti Teknologi Malaysia. His research interest includes the high voltage engineering, electromagnetic field and lightning measurement. 